\title{
Effect of Health Care Professionals' Continuing Education Programme on Diabetic Patients' Outcomes in Mukalla City, Yemen
}

\author{
Salmeen D Babelgaith ${ }^{1 *}$, Mohd Baidi ${ }^{2}$, Mohamed Al-Arifi ${ }^{1}$, Saeed Alfadly ${ }^{3}$ and \\ Syed Wajid ${ }^{1}$ \\ ${ }^{1}$ Clinical Pharmacy Department, Drug and Poison Information Center, College of Pharmacy, King Saud University, Saudi \\ Arabia, '2AIMST University, Bedong, Kedah, Malaysia, ${ }^{3}$ Pharmacy Department, College of Medicine and Health Sciences, \\ Hadramout University, Mukalla, Yemen
}

*For correspondence: Email: drsalmeen@yahoo.com; Tel: +966557895570; 0096614677354; Fax: 0096614674229

\begin{abstract}
Purpose: To evaluate the impact of educational intervention by health care providers on clinical outcomes in type 2 diabetes patients in a Yemeni health facility.

Methods: A prospective, one-group and pre- and post-test design to assess the effects of health care providers' education on clinical patient outcomes was undertaken. The study took place in Al-Noor Charity Clinic (ACC), Mukalla City, Yemen. The subjects of this study were type 2 diabetes patients who received health services at ACC and met the inclusion criteria. Patients' diabetes-related clinical parameter assessed were fasting blood glucose, weight, blood pressure, and lipid profile, i.e., cholesterol, triglyceride (TG), low density lipoprotein (LDL)-cholesterol and high density lipoprotein (HDL)-cholesterol) at baseline, i.e., before the intervention programme, and also at 6 months after the intervention.

Results: There was significant improvement in clinical outcomes: fasting blood sugar $(p=0.004)$, systolic blood pressure $(p=0.003)$ diastolic blood pressure $(p=0.05)$, low density lipoprotein cholesterol $(p=0.005)$ and high density lipoprotein cholesterol $(p=0.001)$, but total cholesterol $(p=$ $0.33)$ weight $(p=0.404)$ and triglyceride $(p=0.056)$ did not improve.

Conclusions: Educational intervention of health care providers program does improve diabetic patients' clinical outcomes.
\end{abstract}

Keywords: Diabetes care; Health care providers, Patients' outcomes, Blood pressure, Lipid profile, Cholesterol, Yemen

Tropical Journal of Pharmaceutical Research is indexed by Science Citation Index (SciSearch), Scopus, International Pharmaceutical Abstract, Chemical Abstracts, Embase, Index Copernicus, EBSCO, African Index Medicus, JournalSeek, Journal Citation Reports/Science Edition, Directory of Open Access Journals (DOAJ), African Journal Online, Bioline International, Open-J-Gate and Pharmacy Abstracts

\section{INTRODUCTION}

Diabetes is a major global health problem. It has been estimated that there are about 366 million diabetes patients worldwide and the majority of them are suffering from diabetes type 2 [1]. It has been postulated that the number of diabetes patients worldwide in the year 2030 could increase to 552 million.
According to Siceree et al, six countries in the Middle East are rated among the top 10 countries in the world with the highest prevalence of diabetes. The 6 countries are the United Arab Emirates, which has the second highest diabetes rate in the world, followed by Bahrain, Egypt, Kuwait, Oman and the Kingdom of Saudi Arabia [2]. Yemen is currently undergoing rapid 
development and is not excluded from the rapid increase in the incidence of diabetes [3]. In the year 2000, the prevalence of diabetes in the whole of Yemen increased from 4.7 to $6.57 \%$ [4]. In 2008, Gunaid and Assabri, reported that the incidence of diabetes in Yemen had increased to $10.4 \%$ [3]. Furthermore, in 2004, the total prevalence of type II diabetes mellitus in the urban cities of Yemen was about $4.6 \%$ (7.4 $\%$ of males and $2 \%$ of females [5]. Moreover, the prevalence of impaired glucose tolerance (IGT) and impaired fasting glucose (IFG) were found to be 2 and $2.2 \%$, respectively [5].

Health care professionals' education programme has been shown to improve the quality of care of diabetes patients and yield the best results in clinical outcomes [6,7]. Several studies have reported that improved glycemic control, reduction in cholesterol and the control of blood pressure (BP) could reduce complications and improve outcomes [7-9].

In this study, we evaluated the impact of professionals' continuing education (CE) programme on the clinical outcomes in type 2 diabetes patients.

\section{EXPERIMENTAL}

\section{Study design}

The study used a prospective, pre- and post-test design to assess the effects of health care providers' education on clinical outcomes in type 2 diabetes mellitus. Pre-test data were collected before education programme was started and also carried out after the intervention.

Approval for conducting this study was obtained from the ethics committee of Ministry of Health (Branch of Hadramout).

\section{Study location}

The setting of the study was an outpatient diabetic clinic of ACC, located in Mukalla. The population of the Mukalla City was approximately 30,000 peoples at the time of the study. The clinic is the only full-service facility dedicated to treating diabetes patients. The total number of diabetes patients in this clinic was about 240 patients. The clinic is located in the centre of Mukalla City, Yemen. It is the only clinic caring for diabetes patients in the city, and is staffed with physicians, nurses and other health care providers. Clinical services are offered daily from 8: $00 \mathrm{am}$ to 1: $00 \mathrm{pm}$ and from 4:00 pm to $9: 00$ $\mathrm{pm}$, except on Fridays and public holidays. A waiting room furnished with chairs and a television to house diabetes education programme.

\section{Health care personnel}

The health care personnel, who were working at ACC and attended the continuing education programmes, included one endocrinologist, three general medical practitioners, four nurses, one pharmacist and one laboratory technician.

Diagnoses, assessment of health status and drug therapy were provided by medical doctors. The pharmacist provided anti-diabetics drugs, blood testing devices, syringes, insulin and other medications. Staff nurses measure vital signs (i.e., blood pressure, temperature) and record that in medical record file.

\section{Study population}

The population of this study consisted of all the type 2 diabetes mellitus patients who received diabetes care services at the ACC and met the inclusion criteria. The inclusion criteria were: confirmed diagnosis of type 2 diabetes for a minimum of 1 year and patients on routine scheduled health visits in the ACC clinic. Exclusion criteria include blindness, severe stroke, kidney dialysis < 18 years of age and persons with diabetes other than type 2 (including type 1, gestational diabetes or secondary diabetes).

\section{Sampling procedure}

The objective of this study was to explore whether health care professionals' education intervention would improve clinical outcomes of type 2 diabetes patients [glycemic control, BP, weight, lipid profiles (total cholesterol, LDL cholesterol, HDL cholesterol and TG)]. A total of 240 patients with T2DM were initially screened by reviewing their medical files. Subjects who met the inclusion criteria were selected. There were 92 out of 240 diabetes type 2 patients who fulfilled the inclusion criteria and were thus included in the study. Those 92 patients routinely received treatment from the outpatient clinic of ACC for their diabetes routine care. Routine care was defined as subjects who consulted health care professionals (HCPs) for diabetes care services on every visit. All selected patients were informed by the Director of the ACC to fast from 12 midnight prior to the day of visit for fasting blood sugar and lipid profile. The subjects were also reminded to comply with the date of visit given to them. Since the laboratories have limited 
capacity to handle samples, the patients were scheduled to come in different weeks. Each week only 10 patients were provided with HCPs interventions.

HCPs that provided intervention to the study patients had recently completed the continuing education programme (August 2009). The interventions given to the study participants included the information on the diseases, diabetes mellitus, drug therapy regimen and compliance, exercise and diets recommended for diabetes patients. Diabetes outcomes measurement

Five measurements of diabetes outcome were collected from the diabetic out-patient medical records. The five parameters collected were fasting blood sugar, body weight, blood pressure, lipid profile and renal profile.

\section{Fasting blood sugar}

Fasting blood sugar was collected every visit, but the reading on the pre-intervention, and six months after the interventions, were recorded in the study form. The patients were required to fast for at least 8 hours from 12 midnight to 8 am the following morning before the blood sample was collected. Blood sugar level was measured using Biochemical Systems International Sri machine (Model: Screen Master 3000) and the result was given in $\mathrm{mg} / \mathrm{dl}$.

\section{Body weight}

The patient's body weight was measured at each visit by the nurses and recorded in the medical record. Body weight prior to intervention, and at six months post-intervention, was then extracted from each patient's medical record.

\section{Blood pressure measurement}

Blood pressure was measured by the doctor using a sphygmanometer after the patients would have been sitting for about $5 \mathrm{~min}$. The blood pressure reading was given in $\mathrm{mmHg}$.

\section{Determination of lipid profile}

Similarly, the patients had to fast before the blood sample for lipid profile was collected. The blood sample was analysed using Biochemical Systems International Sri machine while the results of total cholesterol, LDL, HDL and TG were given in $\mathrm{mg} / \mathrm{dL}$

\section{Statistical analysis}

All the data were transferred to the spread sheet of SPSS version 15 for analysis. The data were checked for normality using Kolmogorov-Smirnov Test and all were found not to be normally distributed. All descriptive data were presented as numbers, frequencies, percentages, means, standard deviations and median. Tables were used, where appropriate, to present the data. Wilcoxon test was used to analyse the significance of variations before and after intervention.

\section{RESULTS}

\section{Patient demographics}

Fifty of the study participants were male (54.3\%) while $42(45.7 \%)$ were females, as shown in Table 1.

Table 1: Demographic profile of participants

\begin{tabular}{|c|c|c|c|}
\hline Patients' profile & Category & $\begin{array}{c}\text { No. of subjects } \\
N=92\end{array}$ & $\%$ \\
\hline & $25-34$ & 3 & 3.3 \\
\hline & $35-44$ & 21 & 22.8 \\
\hline Age (years/months) & $45-54$ & 31 & 33.7 \\
\hline \multirow[t]{3}{*}{ Mean $51.4 \pm 10.4$} & $55-64$ & 24 & 26.1 \\
\hline & $65-74$ & 12 & 13.0 \\
\hline & $75-79$ & 1 & 1.1 \\
\hline \multirow{2}{*}{ Gender } & Male & 50 & 54.3 \\
\hline & Female & 42 & 45.7 \\
\hline \multirow{4}{*}{$\begin{array}{l}\text { Duration of type } 2 \\
\text { diabetes } \\
\text { Mean } 5.3 \pm 4.7\end{array}$} & $1-4$ & 42 & 45.7 \\
\hline & $5-9$ & 33 & 35.9 \\
\hline & $10-14$ & 13 & 14.1 \\
\hline & $15-23$ & 4 & 4.3 \\
\hline \multirow[t]{2}{*}{ Family history } & $\mathrm{DM}$ & 42 & 62.7 \\
\hline & HTN & 25 & 37.3 \\
\hline
\end{tabular}




\section{Fasting blood sugar}

Fasting blood sugar (FBS) was measured at base line and 6 months after intervention. Table 2 shows the means and standard deviations of a FBS at baseline and 6 months after intervention. There was significant difference from pre to 6 months after intervention $(p=0.004)$.

\section{Blood pressure}

Table 2 shows the means and standard deviations of a SBP and DBP at baseline and 6 months after intervention.

The study found significant reduction in both systolic blood pressure (SBP) and diastolic blood pressure (DBP) after the intervention $(p=$ $0.033, p=0.05$ respectively).

\section{Lipid profiles}

All lipid profiles were measured at base line and after 6 months of intervention as shown in table 2.

Significant result was found after 6 months intervention for LDL cholesterol levels $(p=$ 0.005), also significant improvements in HDL cholesterol levels was found at 6 months after intervention $(p=0.001)$.

Unfortunately, there was no significant difference after intervention found for total cholesterol and TG $(p=0.404, p=0.056$ respectively).

\section{Body weight}

There was no significant change in mean body weight from pretest to 6 months after intervention $(p=0.33)$, as shown in Table 2.

\section{DISCUSSION}

One of the desirable chemical outcomes of the diabetes management is reduction of blood sugar level to normal. This blood glucose level was monitored during every patient's visit to the hospital to ensure that the blood sugar fell within normal range. In addition, the blood sugar level was used to monitor the progress of the diabetes. In addition, the blood sugar level, glycosylated Hemoglobin ( $\mathrm{HbA1C}$ ), is used to determine the progress of the diabetes patients. In the case of elevated blood glucose level, the excessive glucose will attach to the hemoglobin, and this attachment will continue for the whole lifecycle of the hemoglobin. Therefore, the $\mathrm{HbA} 1 \mathrm{C}$ is a good parameter to monitor patient compliance with the treatment as it reflects the blood glucose levels over the 3 to 4 months duration. Uncontrolled blood sugar, it has been claimed, is one of the main factors contributing to the development of acute and chronic complications from diabetes $[10,11]$. In this study, diabetes control is monitored by measuring plasma glucose instead of $\mathrm{HbA} 1 \mathrm{C}$ because $\mathrm{HbA} 1 \mathrm{C}$ is not available as a routine test for diabetes monitoring in Mukalla City. The patients have to pay for the cost of $\mathrm{HbA} 1 \mathrm{C}$ monitoring, and therefore it is rarely monitored (6 USD). American Diabetes Association (ADA) recommend that the glycemic control target for inpatients is $110 \mathrm{mg} / \mathrm{dl}(6.1 \mathrm{mmol} / \mathrm{L})$, while for outpatients fasting blood glucose level should be $<126 \mathrm{mg} / \mathrm{dl}$ (7 mmol/L) and random blood glucose readings $<180-200 \mathrm{mg} / \mathrm{dl}(<10-11$ $\mathrm{mmol} / \mathrm{L}$ ) [10]. This study found that the mean baseline FBS level was $160.3 \mathrm{mg} / \mathrm{dl} \quad(8.9$ $\mathrm{mmol} / \mathrm{L})$, which was higher than that recommended $(126 \mathrm{mg} / \mathrm{dL})$. The FBS levels continue to be lower in the subsequent visits: $137.5 \mathrm{mg} / \mathrm{dL}$ after 6 months of intervention by HCPs.

Table 2: Pre-intervention and post-intervention (6 months) values of primary outcomes

\begin{tabular}{|c|c|c|c|}
\hline Primary outcomes & $\begin{array}{l}\text { Pre-intervention } \\
\text { Mean (median ) } \pm S D\end{array}$ & $\begin{array}{c}\text { Post-intervention mean ( } \\
\text { median ) } \pm \text { SD }\end{array}$ & $P$-value * \\
\hline Fasting blood sugar (mg/dl) & $160.3(150) \pm 42.4$ & $137.5(137) \pm 34.07$ & 0.004 \\
\hline $\begin{array}{l}\text { Systolic blood pressure (mm } \\
\mathrm{Hg} \text { ) }\end{array}$ & $126.3(120) \pm 9.1$ & $125.2(120) \pm 14.0$ & 0.033 \\
\hline $\begin{array}{l}\text { Diastolic blood pressure ( } \\
\mathrm{mm} \mathrm{Hg} \text { ) }\end{array}$ & $78.6(80) \pm 8.7$ & $76.8(75) \pm 7.1$ & 0.05 \\
\hline Weight (Kg) & $71.2(69) \pm 15.4$ & $72(67.8) \pm 11.3$ & 0.33 \\
\hline Total cholesterol (mg/dl) & $195.2(190) \pm 31.5$ & $188.9(190) \pm 23.5$ & 0.404 \\
\hline LDL cholesterol (mg/dl) & $128(124) \pm 26.6$ & $114(114) \pm 24.2$ & 0.005 \\
\hline $\begin{array}{l}\text { HDL cholesterol } \\
(\mathrm{mg} / \mathrm{dl})\end{array}$ & $36.8(37) \pm 3.3$ & $47(50) \pm 4.4$ & 0.001 \\
\hline Triglyceride (mg/dl) & $144.3(140) \pm 37.6$ & $133.0(130) \pm 17.3$ & 0.056 \\
\hline
\end{tabular}


The reduction in the FBS from the baseline to the 6 months was significant $(p=0.004)$. This demonstrated that the intervention of the HCPs significantly improved the FBS. The baseline FBS represented the FBS outcome of the intervention by HCPs before CE. On the other hand, the FBS at 6 month represented the FBS outcome after the HCPs had received CE. This result showed that the CE programme of HCPs produces a positive FBS outcome for diabetes patients. The result supports the findings of previous studies that the CE provided to the health care professionals was effective in improving glycemic control of the diabetes patients $[8,11]$.

Hypertension is one of the commonest vascular complications of diabetes [12]. Subsequently, the patient may develop other cardiovascular complications such as coronary artery diseases and heart failure. Previous studies reported that lowering blood pressure to $<140 / 80 \mathrm{mmHg}$ would decrease the incidence of hypertension, coronary heart disease and stroke [13]. ADA (2008) recommends that the blood pressure of diabetes patients should be checked every visit. The recommended target BP in diabetes patients is $<130 / 80 \mathrm{mmHg}$ [10].

This study showed that the BP of the subjects was $126.3 / 78.6 \mathrm{~mm} \mathrm{Hg}$ at baseline and reduced to $<125 / 77 \mathrm{~mm} \mathrm{Hg}$ after the intervention. This supported the findings of previous researchers [14], where HCPs, who had received CE, could reduce the $\mathrm{BP}$ in diabetes patients.

The mean systolic pressure at baseline was $126.3 \mathrm{~mm} \mathrm{Hg}$, and reduced to $125.2 \mathrm{~mm} \mathrm{Hg}$ at 6 months post intervention. The changes in the mean systolic pressure was significantly different from baseline with $p=0.033$ at 6 month after intervention.

Similarly, the mean diastolic blood pressure reduced from baseline to 6 month after intervention. The diastolic BP at baseline was $78.6 \mathrm{~mm} \mathrm{Hg}, 76.8 \mathrm{~mm} \mathrm{Hg}$ at 6 month after intervention. The drop in diastolic blood pressure was significant at 6 months $(p=0.05)$. All these diastolic blood pressure levels were within the ADA 2008 recommended diastolic blood pressure of $<80 \mathrm{~mm} \mathrm{Hg}$ [10].

Obesity and overweight have been associated with the increased risk of diabetes and cardiovascular diseases. In diabetic patients, being obese or overweight will accelerate the development of CVD complications and stroke. A weight reduction programme will delay the development of T2DM in high-risk population and may improve the glycemic control in those who have T2DM [15]. Among the most popular approach programmes for weight reduction are dietary control and physical exercise $[14,16]$

The subject's mean weight at baseline and at 6 month after HCPs intervention was not significantly different $(72.0 \pm 11.3)$. This finding supported the result of the previous studies $[6,17]$. They reported that it was difficult for health care professionals' education programmes to achieve the targeted weight loss, but improved glycemic control may be attained with a modest weight loss of $5 \%$ [18].

According to American Diabetes Association, fasting lipid profiles should be measured at least annually for diabetes patients, and monitored every 2 years for patients with no risk factors. In general, the target of serum lipid levels assessments are total cholesterol $<200 \mathrm{mg} / \mathrm{dl}$, LDL cholesterol < $100 \mathrm{mg} / \mathrm{dl}$, HDL cholesterol > $50 \mathrm{mg} / \mathrm{dl}$ and triglycerides < $150 \mathrm{mg} / \mathrm{dl}$. Stamler et al [18] suggested that hyeprlipidemia is associated with the development of cardiovascular diseases such as coronary artery disease and stroke.

This study found that the lipid levels of the subjects were within the recommended levels. The HDL cholesterol $(36.8 \mathrm{mg} / \mathrm{dl})$ was lower than the recommended level, while the total cholesterol at baseline was $195.2 \mathrm{mg} / \mathrm{dl}$, LDL cholesterol $128 \mathrm{mg} / \mathrm{dl}$ and triglyceride 143.5 $\mathrm{mg} / \mathrm{dl}$, which are within normal ranges. These findings are comparable to previous study [19].

The results showed that the total cholesterol level at 6 months post intervention decreased to $188.9 \pm 23.0 \mathrm{mg} / \mathrm{dl}$. However, the difference was not significant at 6 months after the intervention compared to baseline $(p=0.404)$. Triglyceride (TG) at baseline, at post 6 months of intervention, was within normal range (143.5 and $133 \mathrm{mg} / \mathrm{dl}$, respectively). The level of TG drops to $136 \mathrm{mg} / \mathrm{dl}$ after six months of intervention by HCPS. However, the drop in the level of TG was not significant $(p=0.211)$. As TG levels change rapidly after meals, the level will increase about 1 $-2 \mathrm{~h}$ after heavy meals. Therefore, fluctuation in the reading could represent the dietary pattern of the patient.

The mean LDL cholesterol level at baseline was elevated to $128 \pm 26.6 \mathrm{mg} / \mathrm{dl}$. The LDL levels drop significantly $(p=0.005) 6$ months after intervention by HCPs. Since this fraction of fat is usually associated with cardiovascular diseases, the elevation of LDL in diabetes should be arrested. The presence of high LDL in diabetes 
patients will increase the risk of cardiovascular diseases [20].

The level of HDL cholesterol at baseline was lower than normal $36.8 \pm 3.3 \mathrm{mg} / \mathrm{dl}$. After 6 months of follow-up, the level of HDL started to increase significantly $(p=0.001)$, which meant HDL cholesterol level of $47 \pm 4.4 \mathrm{mg} / \mathrm{dl}$.

In general, this study found that the level of triglycerides and LDL cholesterol were reduced, while the level of HDL was increased. The change of the lipid profile in this study is in line with the desired pattern of lipid profile. Previous studies have shown that the reduction in LDL and triglycerides and the elevation of HDL are associated with the reduction in the risk of cardiovascular events $[13,20]$.

Despite decrease in the TG and total cholesterol, the changes were not significant. This observation is similar to the result of previous research that reported no significant difference in lipid levels of patients receiving interventions from HCP who had attended professionals' education programmes $[6,7,18]$.

\section{Limitations of the study}

This study is the first on healthcare provider' continuing education programme on diabetic patient outcome in Mukalla City, Yemen. Although the findings of this study are promising, it has some limitations. One of the limitations is the design, which used one group for pre- and post-intervention without a control group. The use of a control group will make it possible to avoid biased results. The second limitation is the small sample size. In addition, the research was conducted in one outpatient diabetic clinic. Therefore, the results of this study would only reflect the situation in Mukalla City, not the whole of Yemen.

\section{CONCLUSION}

This study provides evidence that health care professionals' continuing education (CE) programme in diabetes and its management plays an important role in the improvement of patient clinical outcomes.

\section{ACKNOWLEDGEMENT}

The authors would like to acknowledge the study participants' for giving up their precious time to be a part of this study.

\section{REFERENCES}

1. Whiting DR, Guariguata L, Weil C, Shaw, J. IDF diabetes atlas: global estimates of the prevalence of diabetes for 2011 and 2030. Diabetes Res Clin Pract. 2011; 94(3) 311-321.

2. Shaw J, Sicree BR, Zimmet $P$. The Global Burden Diabetes and Impaired Glucose Tolerance. Diabetes 1978; 27: 1-105.

3. Gunaid AA, Assabri AM. Prevalence of type 2 diabetes and other cardiovascular risk factors in a semirural area in Yemen. Eastern Mediterr Health J. 2008; 141):42-55.

4. Gunaid, AA. Prevalence of known diabetes and hypertension in the Republic of Yemen. East Mediterr Health J. 2002; 8(2-3): 374-385.

5. Al-Habori M, Al-Mamari M, Al-Meeri A. Type II Diabetes Mellitus and impaired glucose tolerance in Yemen: prevalence, associated metabolic changes and risk factors. Diabetes Res Clin Pract. 2004; 65(3): 275281

6. Thom $\mathrm{DH}$, Tirado MD, Woon $T L$, McBride MR. Development and evaluation of a cultural competency training curriculum. BMC Med Educ. 2006; 38(6):1-9.

7. Sperl-Hillen JM, O'Connor PJ, Rush WA, Johnson PE, Gilmer T, Biltz G, Asche SE, Ekstrom HL. Simulated Physician Learning Program Improves Glucose Control in Adults With Diabetes. Diabetes Care. 2010; 33(8): 1727-1733.

8. Renders CM, Valk GD, Griffin SJ, Wagner EH, Eijk VJ, Assendeflft WJ. Interventions to improve the management of diabetes in primary care, outpatient, and community settings: $A$ systematic review. DiabetesCare. 2001; 24(10): 1821-1833.

9. Norris SL, Lau J, Smith J, Schmid CH, Engelgau, MM. Self-Management Education for Adults With Type 2 Diabetes. Diabetes Care. 2002; 25(7): 1159-1171.

10. American Diabetes Association 2008. Standards of medical care. Diabetes Care.

11. Van Zyl DG, Rheeder P. Physician education programme improves quality of diabetes care. S Afr Med J. 2004; 94(6): 455-459.

12. Michael J, Fowler M. Microvascular and Macrovascular Complications of Diabetes. Clinical Diabetes 2008; 26(2): 2 77-282.

13. Stamler J, Vaccaro O, Neaton JD, Wentworth $D$. Diabetes, Other Risk Factors, and 12-Yr Cardiovascular Mortality for Men Screened in the Multiple Risk Factor Intervention Trial. Diabetes Care. 993; 16(2): 434-444.

14. Vinicor F, Cohen SJ, Mazzuca SA, Moorman N, Wheeler $M$, Kuebler $T$, Swanson S, Ours $P$, Fineberg SE, Gordon EE et al. Diabeds: A randomized trial of the effects of physician and/or patient education on diabetes patient outcomes. J Chronic Dis. 1987; 40(4): 345-356. 
15. Hensrud D. Dietary Treatment and Long-Term Weight Loss and Maintenance in Type 2 Diabetes. Obes Res. 2001; 9(4): 348-353.

16. Fett C, Fett W, Fabbro A, Marchini AJ. Dietary Reeducation, Exercise Program, Performance and Body Indexes Associated with Risk Factors in Overweight/Obese Women. JInt Soc Sports Nutr. 2005;2(2): 45-53.

17. Aubert Re, Herman Wh, Waters J, Moore W, BL, P. Nurse case management to improve glycemic control in diabetic patients in a health maintenance organization. Ann Intern Med. 1998; 129(8): 605-612.

18. Taylor $C B$, Miller NH, Reilly $K$, Greenwald G, Cunning $D$, Deeter A, Abascal L. Evaluation of a Nurse-Care
Management System to Improve Outcomes in Patients With Complicated Diabetes. Diabetes Care. 2003; 26(4): 1085-1062.

19. Al-Khawlani A, Raja Y, Al-Ansi A. Hypertension in Yemeni patients with type II diabetes and its association with vascular complications. Heart Views 2009; 10(2): 56-62.

20. Pyörälä K, Pedersen TR, Kjekshus J, Faergeman O, Olsson AG, Thorgeirsson G. Cholesterol lowering with simvastatin improves prognosis of diabetic patients with coronary heart disease: a subgroup analysis of the Scandinavian Simvastatin Survival Study (4S). Diabetes Care. 1997; 20(4): 614-620. 